\title{
Lubricity of new Tailor-Made Fuels from Biomass
}

\author{
A. Weinebeck, H. Murrenhoff \\ IFAS, RWTH Aachen University, Aachen, Germany \\ E-mail: Alexander.Weinebeck@ifas-rwth.aachen.de, \\ Hubertus.Murrenhoff@ifas-rwth.aachen.de
}

\begin{abstract}
The interactions of new biofuels and standard engine components are being investigated at the Institute for Fluid Power Drives and Controls (IFAS) at RWTH Aachen University as part of the research of the cluster of excellence "Tailor-Made Fuels from Biomass". Since modern common rail fuel pumps are fuel lubricated special interest lays on the lubricity of new fuels. At IFAS a High Frequency Reciprocating Test Rig (HFRR) is used to screen possible biofuel candidates with regard to this property. Most of these substances show lubricating abilities similar to those of modern diesel fuels. Nevertheless with 2-Methyltetrahydrofuran a remarkable outlier can be found among the favoured fuel candidates. To unravel the influences of certain molecule structures additional substances were included into the experimental research. By comparing the wear scars of linear alkanes, alkenes and alcohols produced in the HFRR the influence of the molecules chain length and functional group is analysed. This paper gives an introduction to the HFRR test set up and presents the experimental results of the recently screened biofuel candidates.
\end{abstract}

Keywords: Biofuel, Lubricity, HFRR, Tailor-Made Fuels from Biomass

\section{The Cluster of Excellence "Tailor-Made Fuels from Biomass"}

Due to the exploitation of non-renewable resources in modern times some significant effort is put in the development of alternative concepts of mobility. One approach to this task is the usage of the highly sophisticated technology of combustion engines in combination with fuels based not on mineral oil but on renewable biological materials such as food wastes or wood. Within the cluster of excellence "Tailor-Made Fuels from Biomass" at RWTH Aachen University such new biofuels are being developed and tested in an interdisciplinary approach, see Figure 1.

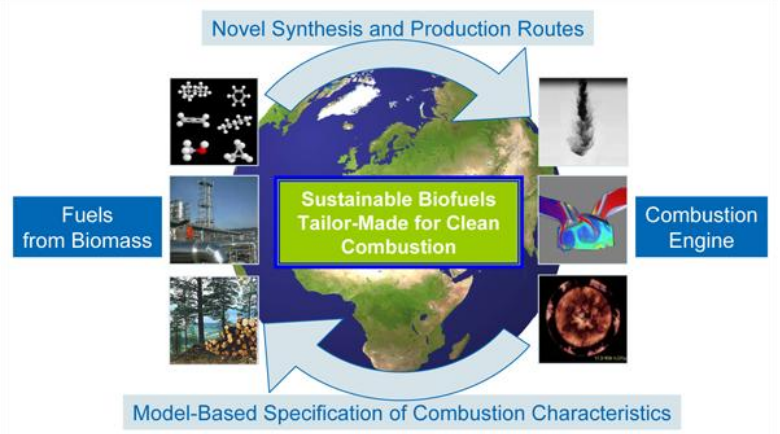

Figure 1: The cluster of excellence Tailor-Made Fuels from Biomass

\section{The Research at the Institute for Fluid Power Drives and Controls}

Viscosity, bulk modulus and lubricity are important properties concerning the handling of a fuel within a combustion engine and its periphery. All of these properties are being investigated at the Institute for Fluid Power Drives and Controls (IFAS), as part of the cluster of excellence. Since modern common rail systems operate with selflubricating fuel pumps (see Figure 2) the fuel lubricity and viscosity are critical criteria judging the possibility of a future usage of a proposed biofuel.

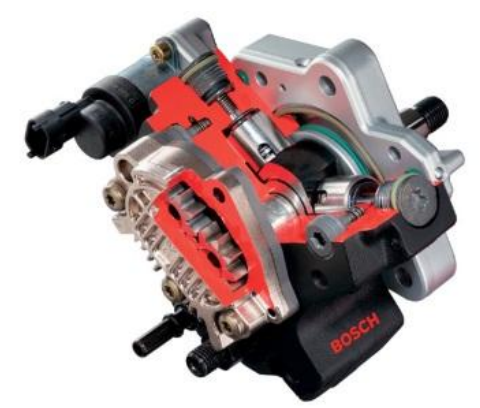

Figure 2: Common rail pump. Source: Robert Bosch GmbH

The so far investigated biofuel candidates tend to have significantly lower viscosities against temperature and 
pressure compared to modern diesel fuels. Since most of the candidates also perform badly as lubricants the safe and reliable combination of these biofuels and modern engine equipment such as common rail fuel pumps becomes a difficult task. In spite of this the usage of these substances as part of a future biofuel could be favourable or even necessary due to their performance or properties in other fields of interest such as combustion.

To enable the widespread usage of new biofuels in the future, the cluster's research has covered the compatibility related topics from the very beginning of the fuel development. The research at IFAS is part of this branch of the cluster with two subprojects:

On the one hand, closely linked experimental and theoretical studies are performed to unravel potential modifications of the standard components (micro and macro geometry, materials, coatings, etc.) to ensure a safe and efficient use of these in combination with the new biofuels [1].

To do so the tribologicaly relevant fluid properties need to be known. Consequently all substances that emerge from the research within the cluster are systematically being screened. Beside the investigations of the fluid's lubricity these tests include measurements of the density, the bulk modulus and the dynamic viscosity as functions of pressure and temperature. Another important research topic at IFAS is the compatibility of the biofuel candidates and sealing materials. Furthermore models to calculate or predict the fluid's behaviour are being developed. First measurements indicate that good lubricating fuel-candidates also perform well as lubricating additives in other fuels including biofuels. Consequently the performances of selected fuelblends are investigated [2].

This paper deals with the performance of unblended biofuel candidates in a standardised fuel-lubricity test.

\section{The High Frequency Reciprocating Test Rig}

The importance of a sufficiently high lubricity of fuels became a topic of increased research after the introduction of low sulphur diesel fuels during the mid-nineties of the last century. Due to the hydrotreatment used in the production of these fuels most of the fuel inherent lubricants were removed. This lead to increased friction and wear within the tribological contacts of the fuel-lubricating pumps and therefore drastically decreased the life expectancies of such systems. To prevent the lubricity based failures tests such as the High Frequency Reciprocating Test Rig (HFRR) were developed and standardised (see [3], [4]). At IFAS such a test rig is used to measure the lubricity of different fluids including biofuel candidates (see Figure 3).

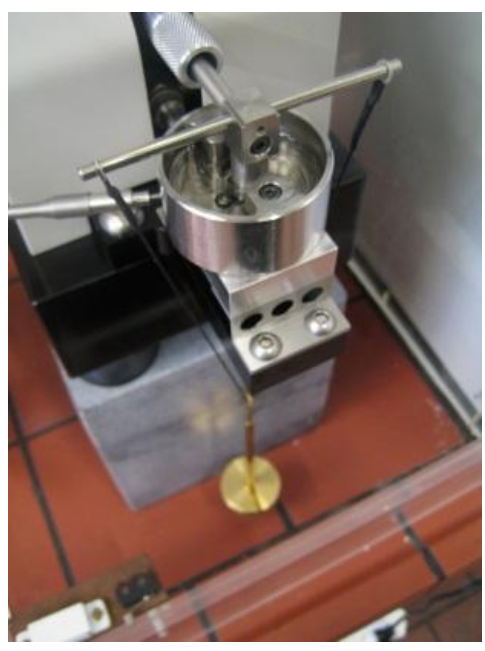

Figure 3: The HFRR at IFAS

The Figure 4 shows the principal design of the HFRR as given in [3]. A disk made of 100Cr6 steel (Vickers hardness "HV30" of 190 to 210) is mounted in a basin containing a sample of $2 \mathrm{ml}$ fuel to be investigated. Against the surface of the disk a 100Cr6 steel ball (Rockwell hardness in "C-scale" 58 to 66$)$ is pressed. The ball is mounted in the reciprocating arm and the contact force is delivered by an external weight of exactly $200 \mathrm{~g}$ that is attached to the arm (see Figure 3 and Figure 4).

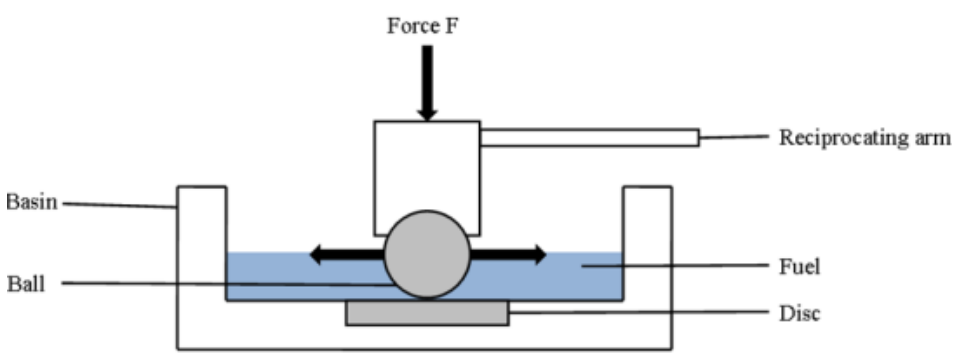

Figure 4: Test setup of the HFRR [1]

Prior to the experiment's start the investigated fluid sample is heated up to $60^{\circ} \mathrm{C}$ and kept at this temperature until the test ends. Some of the investigated substances have boiling points relatively close to $60^{\circ} \mathrm{C}$. To include these in the research, the described set up needs to be altered. Hence for all substances with a boiling point lower than $100{ }^{\circ} \mathrm{C}$ an increased fuel sample of $10 \mathrm{ml}$ was used.

During each test the arm oscillates for a given time and frequency in a reciprocating stroke rubbing the two probes against each other. DIN EN ISO 12156-1 gives the test duration as 75 minutes with a frequency of $1 \mathrm{~Hz}$ for the stroke.

This process leads to typical wear scars on the surfaces of the ball and the disk (see Figure 5). 


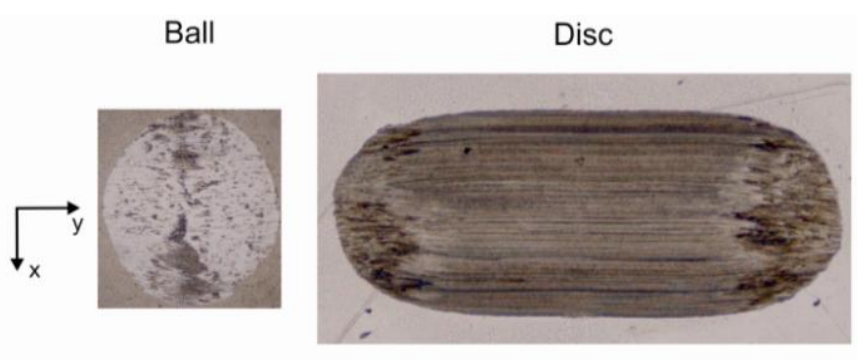

Figure 5: Wear scars of the lower (Ball) and upper (Disc) specimen after a test with cyclohexanone

After each test the probes need to be evaluated with an optical microscope as shown in Figure 6.

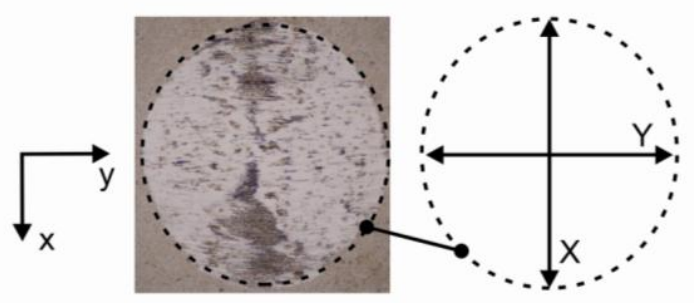

Figure 6: Determination of the wear scar diameter on the ball

The wear scar diameter (WSD) value of the specimen, ball and disc alike, is determined by averaging the latitude of the scars in direction of the oscillation $(\mathrm{Y})$ and vertical $(\mathrm{X})$ to it as given in eq. 1 (see Figure 6).

$$
\mathrm{WSD}=\frac{X+Y}{2}
$$

Both DIN EN ISO 12156-1 and ASTM D6079 use the averaged wear scar diameter of the ball to determine the fluid's lubricity. However Fatemimoughari et al. have reported that for substances with very good lubricating abilities no measurable wear could be found on the ball [8]. To avoid such problems while investigating the highly unknown tribological properties of the substances proposed by the cluster, it was decided to include the wear scars of the discs into the evaluation.

Varying levels of temperature and humidity can influence the measured $W S D$ value. To compensate this, a corrected wear scar diameter - the WS1.4 - was developed. The WS1.4 is widely used and a maximum value of $460 \mu \mathrm{m}$ has been proposed by the European Committee for Standardization as an acceptable value for safe field performances [3]. However, as Lacey and Howel have shown this correction is not valid for different types of (diesel) fuels [4]. Since the investigation of the biofuel candidates proposed by the cluster requires screening a vast number of non-similar substances the uncorrected WSD value is used for the research at IFAS [2].

To minimize statistical errors due to uncertainties each test is repeated at least two times. Each of the WSD values presented in this paper gives therefore the arithmetical mean value of three specimens.

Fatemimoughari has shown that small amounts of a substance with good lubricating properties can drastically reduce the measured wear scar in other fluids [2]. Consequently impurity in the investigated sample of a fluid can have a huge effect on the measured lubricity. An analysis of the composition of each fuel sample provided to our lab is not feasible. Therefore the experimental results of all investigated fluids will be listed with their minimum purity as given by the producer.

\section{Previous research on Biofuel Lubricity at IFAS}

At the beginning of the research on the lubricity of biofuel candidates at IFAS the list of proposed substances was limited. About ten substances were available at the clusters start or shortly after. Consequently these were screened. To gain a more detailed understanding of the properties influencing a fuels capability to reduce wear and friction in the HFRR several additional substances were also tested ([2], [8]). In Figure 7 some of these early results are shown.

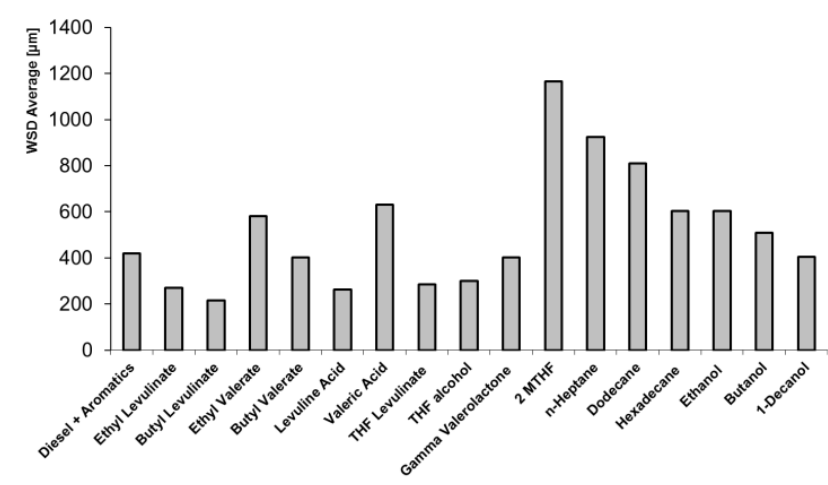

Figure 7: Wear scar diameters of the fluids previously investigated by Fatemimoughari [2]

The research performed by Fatemimoughari et al. showed that although quit different to conventional diesel fuel most biofuel candidates would pass the critical mark of $460 \mu \mathrm{m}$ or produce only slightly more serve wear scars. There are however some remarkable outliers such as 2-Methyltetrahydrofuran and (2-MTHF) and Butyl-Levulinate. With a $W S D$ value of $216,5 \mu \mathrm{m}$ for the ball the latter performs outstandingly well in protecting the specimen and can be used as a lubrication additive in other fuels [2]. 2-MTHF on the other hand, favoured by some institutions within the cluster due to its good performance as a fuel, has produced the highest wear (Ball WSD $=1165,4$ $\mu m$ ) of all fluids so far recorded. Please note that this value differs from the one presented in Table 2 at the end of the paper. The reason for this mismatch is most likely caused by the different purities of the investigated samples. We used a fluid with $99.0 \%$ purity whereas Fatemimoughari was provided with a sample of $99.8 \%$ purity $2-$ MTHF. Since the $99.0 \%$ sample is going to be used in several upcoming investigations dealing with fuel blends its WSD value is presented as well. 
The effect of low viscosity (bio)-fuels on conventional fuel equipment is a topic of on-going scientific research (e. g. see [1], [2]). Without further knowledge of the tribological system and underlying processes a suitable pass/fail criteria to judge a fuel's compatibility can hardly be specified at this point. Therefore the experimentally determined lubricities will be listed without relating them to any prediction on the usage of these substances as fuels.

In the past five years the list of proposed substances with favourable properties with regard to their potential as a biofuel has steadily increased. As a matter of fact the number of candidates and complementary substances being investigated within the cluster has come close to the number of tests that can be performed economically. This raises the need to screen substances in an even faster and more efficient way than performing experiments with the HFRR. Such a predictive model is even more desirable taking into account that the production of the necessary volume (approximately $10 \mathrm{ml}$ ) of an exotic fuel-candidate can take up to several weeks. Therefore the available amount of the fluid is limited.

Consequently a prediction-method for the lubricity of biofuel candidates has been developed during the first phase of the cluster of excellence. By correlating the experimental data with quantum chemical calculations, based on the chemical structure of the substance, a QSPR-Model was set up ([2], [8]). The model has been trained with an external data-set dealing with substances similar to those investigated in the cluster [16]. The necessary calculations were performed with the chemical simulation software COSMO-RS in cooperation with the Institute of Technical Thermodynamics (LTT) at RWTH Aachen University.

Fatemimoughari et al. have shown that the established QSPR-model can be used to give a first estimation of a molecule's lubricating abilities (e.g. Figure 8). A comparison of some experimental and predicted wear scar diameters of a selection of investigates substances is given in [8].

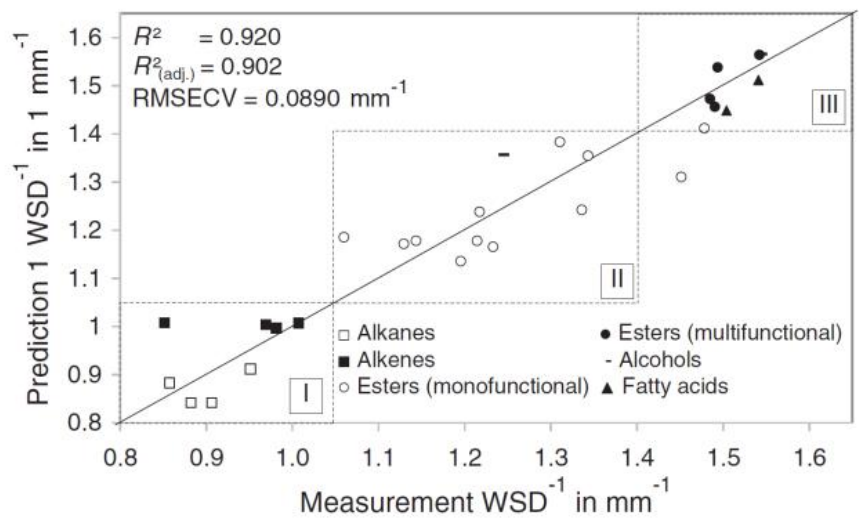

Figure 8: Plot of the predicted vs. measured WSD [8]

Since the QSPR-model only enables a preliminary evaluation of the fuel candidates experimental screening of the more favourable ones is still necessary and has been performend continuously.

To gain a better understanding of the lubricating progress and to increase the accuracy of the prediction model several additional experimental studies with different kinds of substance have been performed at IFAS and will be presented in the next paragraph. These results will be used to further increase the prediction capabilities of the QSPR model. This is especially important since the progress in the cluster has and will shift the focus of its research towards new types of substances.

\section{Lubricity of selected biofuel candidates and similar substances}

The protection of the metal surface by the lubricant is a highly complex procedure which cannot be ascribed to a single property of the fluid's molecules. Nevertheless we have arranged the HFRR test results of all recently screened fluids in Table 2 and Table 3 into groups of molecules with similar structures (The tables are put at the end of the paper to increase the readability). The presented results include the averaged wear scars of both specimens as explained above. In case of 2-Butylfuran and Di-n-Butylether one of the three ball specimens could not be evaluated and the presented WSD values therefore give the arithmetical mean of the remaining two probes. However the corresponding discs could be analysed.

Taking into account that the so far proposed biofuel candidates are taken from very different types of organic substances such as alcohols, ethers, ketones and furans, the understanding of their lubricating abilities by comparing their WSD values becomes a rather difficult task. To overcome this hindrance several additional substances were included into our research. These fluids were chosen due to certain similarities or differences they show when compared to a biofuel candidate. One example for this is the investigation of 1-Octanol, which has been added to the clusters research due to it's favourable properties as a fuel. To analyse the lubricity of this substance other linear molecules such as alkanes and other alcohols were screened. Screening results are discussed in the next chapter. Due to the high variation of the chemical and physical properties of the selected biofuel candidates such comparative experiments cannot be performed for all of them. To illustrate the influence of certain properties a discussion on selected molecules from the list will be given. For complementary reasons five measurements performed by Fatemimoughari are included lubricity in the following discussion (see Table 4 at the end of the paper).

\subsection{Lubricity of linear molecules}

By adsorbing to the metal surfaces the molecules of a lubricant can reduce the friction and wear occurring in a contact (see Figure 9) [15]. 


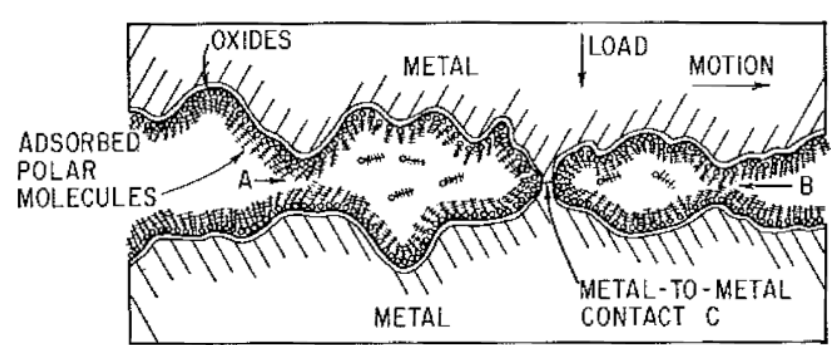

Figure 9: Protective layers of adsorbed polar molecules [15]

The formation of the protective layer of adsorbed molecules is complex and influenced by all characteristics of the tribological system such as the structure of the lubricants molecules and those of the surface material ([14], [15]). Since the set up of the HFRR test, including the material of the specimen, is given only the lubricants properties influence the built up and performance of the protective layers present during the lubricity experiments.

The functional groups of linear molecules are known to influence tribological phenomena such as friction [15]. To investigate whether such an influence is present in the performed HFRR experiments as well, similar molecules with different functional groups need to be investigated. The molecules of $\mathrm{n}$-dodecane, $\mathrm{n}$-dodecene and 1-dodecanol are all composed of twelve carbon atoms (see Figure 10).

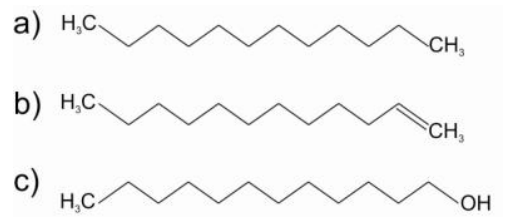

Figure 10: Molecule structures of a) n-dodecane, b) n-dodecene and c) 1-dodecanol

Since they have a similar size the influence of their functional groups can be derived by comparing their WSD values (see Table 1).

\begin{tabular}{|l|l|c|}
\hline Formula & Substance & WSD Ball [ $\boldsymbol{\mu m}]$ \\
\hline $\mathrm{C}_{12} \mathrm{H}_{26}$ & n-Dodecane & 810,0 \\
\hline $\mathrm{C}_{12} \mathrm{H}_{24}$ & 1-Dodecene & 635,0 \\
\hline $\mathrm{C}_{12} \mathrm{H}_{26} \mathrm{O}$ & 1-Dodecanol & 344,5 \\
\hline
\end{tabular}

Table 1: The Wear scar diameters of the investigated $C_{12}$ molecules

The alcohol group (-OH) of the linear alcohols, such as 1dodecanol, has a relatively high "polarity" when compared to the functional groups of alkanes and alkenes. In [19] Hsu defines this "polarity" as a function of several molecule properties such as the reactivity of the functional group and molecules shape. In the presences of other polar molecules such as metal oxides these molecules therefore will form stronger bonds with the atoms of the specimen's surface. As sketched in Figure 11 the combination of a long carbon chain and a polar head group leads to a perpendicular alignment of the molecules on the surface which further increases the protection of the metal [14].

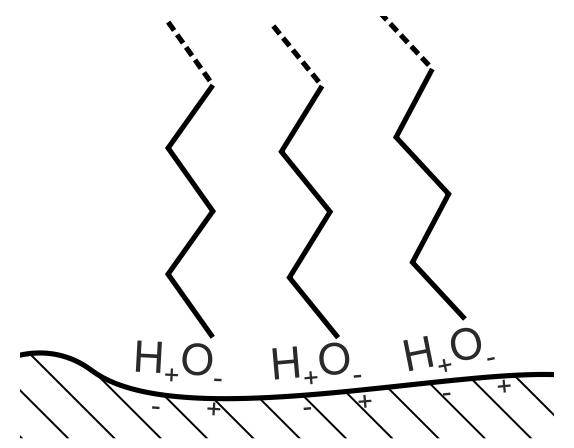

Figure 11: Alignment of adsorbed polar molecules

Since the molecules of alkanes and alkenes do not possess a head group with a high polarity the bonds between the surface and the lubricant's molecules will be weaker and the molecules will adsorb to the surface in a more or less random fashion. Consequently such substances provide a less effective protection from wear in the HFFR as can be seen in Table 1.

In Figure 12 the $W S D$ values of three alkanes, four alkenes and six alcohols form Table 2 are given as function of the amount of carbon atoms in each molecule. In the graph the averaged values of three specimens are presented including the maximum and minimum WSD measured. Please note that for comparative reasons some measurements performed by Fatemimoughari were included into the graph (see Table 4). The geometrical forms of these molecules are quiet similar since all of them have a chain structure without branches (see Figure 10). The simple linear structure of these molecules can be used to analyse the influence of the molecule elongation.

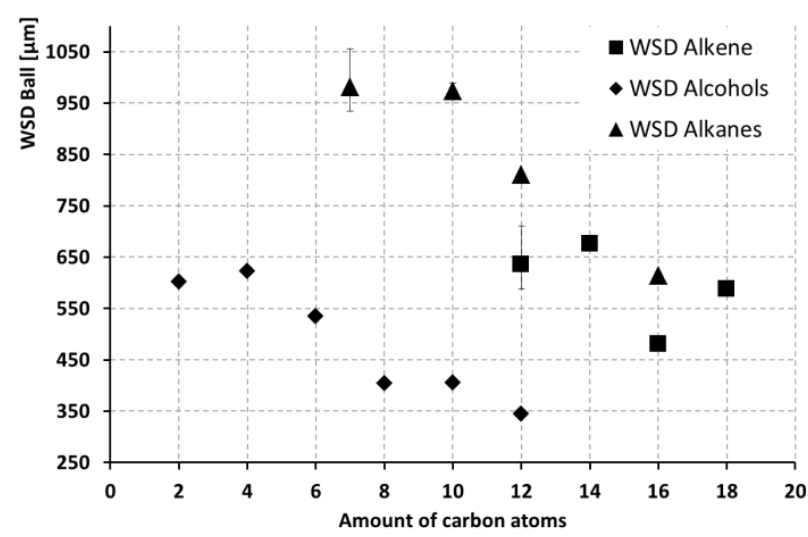

Figure 12: Wear scar diameters of the investigated alcohols, alkenes and alkanes

The investigated alcohols and alkanes show a clear tendency towards a better lubricity with increasing chain-length. The experimental results of the presented alkenes did not produce such pronounced behaviour. Although the WSD values increase from 1-Dodecene to 1-Tetradecene and from 1-Hexadecene to 1-Octadecene the overall trend also shows a decreasing wear over the increasing chain length. The 
decrease of wear in the tribological system of the HFRR in the presence of long chain molecules with a polar head group is in compliance with the results of Studt [18]. By studying the influence of the chain length of polar molecules on the friction between metal and ceramic surfaces, he found that for metal surfaces molecules with polar head groups and long carbon chain could decrease the friction the most.

\subsection{Lubricity results of more complex molecules}

Some of the linear molecules discussed above are among the favoured candidates of potential biofuels within the cluster of excellence. However most of the proposed candidates have far more complex structures such as the molecule of 2,2'-Oxybis(methylene)bis(tetrahydrofuran) given in Figure 13.

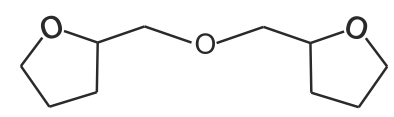

\section{Figure 13: The molecule structure of 2,2'-oxybis(methylene)bis(tetrahydrofuran)}

The shortage of experimental data concerning these and similar molecules limits investigation of their specific properties. However the lubricating performance of these fuels is still important and needs to be taken into account when dealing with them in test rigs or combustion engines. Among the investigated fluids 2,5-Dimethylfuran and Benzyl alcohol performed best in protecting the metal surface by producing a $W S D_{\text {Ball }}$ of only $300,5 \mu \mathrm{m}$ respectively $303,0 \mu \mathrm{m}$ on the upper specimen. In contrast the two worst lubricating abilities were measured for 2-Methyltetrahydrofuran with a $W S D_{\text {Ball }}$ of $855,1 \mu \mathrm{m}$ and n-Heptane with a $W S D_{\text {Ball }}$ of 925,0 $\mu m$ (see Figure 14).

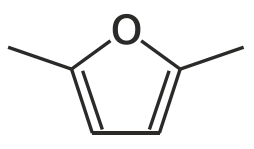

2,5-Dimethyfuran<smiles>CC1CCCO1</smiles>

2-Methyltetrahydrofuran<smiles>OCc1ccccc1</smiles>

Benzyl alcohol

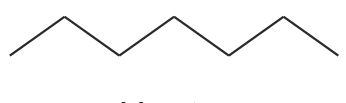

n-Heptane
Figure 14: Molecule structure of the best (top) and worst (bottom) lubricants

The bad performance of n-Heptane, which is the shortest of the investigated alkanes, follows consequently from the phenomena discussed above. In the case of 2-MTHF Fatemimoughari et al. have suspected that the steric hindrance of the methyl group prevents a good surface coverage [9]. Considering the similar molecule structure of 2,5-Dimethylether and its outstandingly good lubricating properties this explanation seems to be implausible. Consequently the unsatisfactory performance of 2-MTHF and its understanding will be part of future research.

\subsection{The influence of the fuel viscosity}

In the Figure 15 the lubricity values of the investigated alkenes and alcohols are combined with the dynamic viscosities of the investigated alkenes and alcohols at $25^{\circ} \mathrm{C}$. Please note that these are taken from literature (see [17]) due to small amount of fluid available. For both groups the viscosities increase over the chain length and the wear decreases. However the changes do not follow a similar trend.

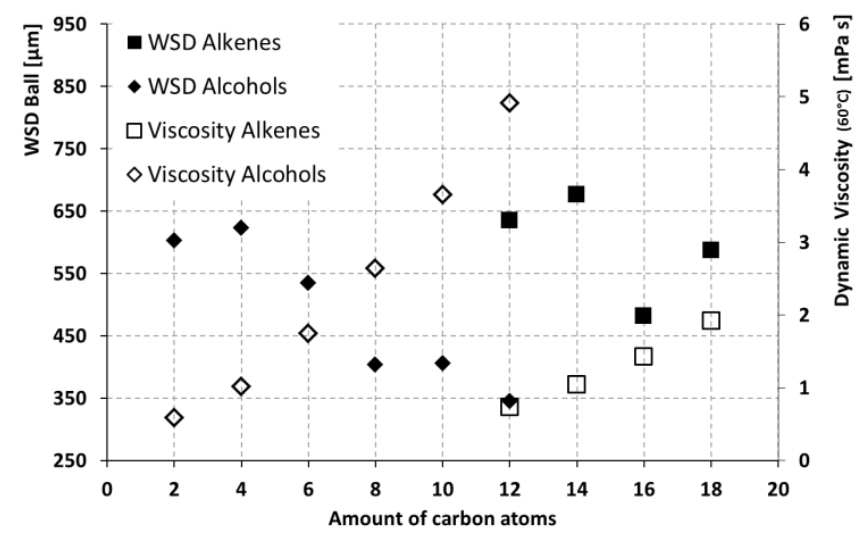

Figure 15: Comparison of the lubricity and dynamic viscosity

Wei et al. published a hypothesis that the decrease of the $W S D$ values among alkanes with longer chain length is due to the increase of the dynamic viscosity and its influence in the built up of an hydrodynamic film between the two specimen [11].

Sivebaek et al. have investigated the performance of alkanes in the regime of boundary lubrication theoretically with molecular dynamic simulations ([12], [13]). Contrary to Wei et al. they do not ascribed the reduced wear mainly to the increase in the dynamic viscosity. In their simulations they found that a longer chain-length resulted in a higher surface density of the investigated fluid molecules which would lead to a better protection of the metal atoms. Considering the steep rise in the viscosity from 1-Octanol $\left(\mathrm{C}_{8} \mathrm{H}_{18} \mathrm{O}, \eta=\right.$ 2,643 $\mathrm{mPas}$ ) to 1-Decanol $\left(\mathrm{C}_{10} \mathrm{H}_{22} \mathrm{O}, \eta=3,565 \mathrm{mPa} \mathrm{s}\right)$ and the nearly constant lubricities of the two substances the hypothesis presented by Sivebaek seems to give a more suitable description of the present phenomena.

A more detailed discussion on the theoretical effects of the molecule chain length and the influence on the fuels viscosity is given in [2]. 


\section{Conclusion and Outlook}

The experimental procedure to screen biofuel candidates with regard to their lubricity at the Institute for Fluid Powers and Controls (IFAS) with a HFRR test rig has been presented. The WSD values of 27 investigated fluids were given. This group includes alkanes, alkenes, alcohols, aldehydes, furanes and ketones. By comparing the results of selected substances the influence of molecules chain length and polar head groups have been investigated. In case for linear molecules such as alkanes the lubricity increases with the length of carbon chain. Molecules with polar head groups, such as the investigated linear alcohols, perform better in protecting a metal surface than molecules of similar size that do not feature such structures. Among the screened substances 2,5-Dimethylfuran showed the best and 2-Methyltetrahydrofuran the worst lubricating abilities.

Due to the novel and fundamental character of the research performed within the cluster of excellence a wide spread and steadily increasing selection of possible biofuel candidates are being investigated. These will be screened and evaluated according to the procedures described in this paper.

In addition to this a set of favourable biofuel blends has been formulated by some of the cluster's researchers. The lubricating performance of binary blends is highly nonlinear [2] and cannot be derived by averaging the pure substances WSD values. Therefore the behaviour of fuel-blends will be investigated by experimental and theoretical research.

To develop and improve fast screening methods is important when dealing with a vast number of possible fuel candidates. Consequently the lubricity data presented in this paper will be used to improve the QSPR prediction model that has been developed by Fatemimoughari et al.

Since the lubricity of fuel blends will be an essential part of the upcoming experimental research, the QSPR-Model will be extended to cover these as well.

\section{Nomenclature}

\begin{tabular}{lll}
\hline Designation & Denotation & Unit \\
\hline$X$ & $\begin{array}{l}\text { Wear scar diameter vertical to the } \\
\text { direction of oscillation }\end{array}$ & {$[\mu \mathrm{m}]$} \\
$Y$ & $\begin{array}{l}\text { Wear scar diameter in the } \\
\text { direction of oscillation }\end{array}$ & {$[\mu \mathrm{m}]$} \\
$W S D$ & Averaged wear scar diameter & {$[\mu \mathrm{m}]$} \\
$W S 1.4$ & Corrected wear scar diameter & {$[\mu \mathrm{m}]$} \\
$\eta$ & Dynamic viscosity & {$[\mathrm{Pa} \mathrm{s}]$} \\
\hline
\end{tabular}




\section{References}

[1] Heitzig, S., Leonhard, L., Drumm, S., Murrenhoff, H., Lang, J. \& Knoll, G. (2013), Simulative Analysis of the Tribological Contacts of Common Rail InjectionPumps Lubricated by Tailor-Made Biofuels, Tribologie und Schmierungstechnik, 6, 17-22.

[2] Fatemimoughari, A. Analysis of Tribological Properties for the Design of Synthetic Biofuels. Shaker, Aachen, 2012.

\section{[3] DIN EN ISO 12156-1}

\section{[4] ASTM D6079}

[5] Nikanjam, M., Crosby, T., Henderson, P., Gray, C., Meyer, K., Davenport, N. ISO diesel fuel lubricity round robin program. SAE Transactions, 104, 1995.

[6] DIN EN 590.

[7] Lacey, P.I., Howell, S.A., Fuel lubricity reviewed. Society of Automotive Engineers, 1998

[8] Masuch, K., Fatemimoughari A., Murrenhoff, H. and K Leonhard. A COSMORS based QSPR model for lubricity of petro- and biodiesel components. Lubrication Science, online, 2011.

[9] Fatemimoughari, A., Masuch K., Murrenhoff, H., Leonhard, K., Experimental investigation and theoretical prediction of the lubricity of biofuel components, Fluid Power and Motion Control Symposium, Bath, 2010

[10] Barbour, R., Rickeard, D., and Elliott, N., Understanding Diesel Lubricity. SAE Technical Paper 2000-01-1918, 2000

[11] Wei, D., Spikes, H., Korcek, S., The lubricity of gasoline. Tribology transactions, 42, 1999

[12] Sivebaek, I. M., Samoilov, V.N., Persson, B.N.J., Squeezing molecular thin alkane lubrication films between curved solid surfaces with long-range elasticity: Layering transitions and wear, Journal of chemical physics, 119, 2003

[13] Tartaglino, U., Sivebaek, I. M., Persson, B. N.J., Tosatti, E., Impact of molecular structure on the lubricant squeeze-out between curved surfaces with long range elasticity, Journal of chemical physics, 125, 2006

[14] Czichos, H., Habig, KH., Tribologie-Handbuch; Reibung und Verschleiss, Vieweg, Wiesbaden, 1992.
[15] O'Connor, J. J (editor)., Standard handbook of lubrication engineering, McGraw-Hill, New York, 1968

[16] Knothe, G., Evaluation of ball and disc wear scar data in the HFRR lubricity test. Lubrication Science, 20, 2008

[17] Wohlfarth, C. and Wohlfarth, B., Viscosity of Pure Organic Liquids and Binary Liquid Mixtures, Subvolume B: Pure Organic Liquids, Springer-Verlag: Berlin, Heidelberg, New York, 2001

[18] Studt, P., Boundary lubrication: adsorption of oil additives on steel and ceramic surfaces and its influence on friction and wear, Tribology international, 22, 1989

[19]Hsu, S., Molecular basis of lubrication, Tribology International, 37, 2004 
The 13th Scandinavian International Conference on Fluid Power, SICFP2013, June 3-5, 2013, Linköping, Sweden

\begin{tabular}{|c|c|c|c|c|c|}
\hline & & & \multirow{2}{*}{\multicolumn{3}{|c|}{ Ball specimen }} \\
\hline & & & & & \\
\hline Formula & Substance & Purity & $\begin{array}{c}\text { Averaged } W S D \\
{[\mu \mathrm{m}]}\end{array}$ & $\underset{[\mu \mathrm{m}]}{\operatorname{Maximum}} \boldsymbol{W S D}$ & $\underset{[\mu \mathrm{m}]}{\operatorname{Minimum}} W S D$ \\
\hline $\mathrm{C}_{7} \mathrm{H}_{16}$ & n-Heptane & $99,0 \%$ & 980,8 & 933,8 & 1055,8 \\
\hline $\mathrm{C}_{10} \mathrm{H}_{22}$ & n-Decane & $99,0 \%$ & 972,7 & 963,4 & 988,24 \\
\hline $\mathrm{C}_{16} \mathrm{H}_{34} \mathrm{O}$ & n-Hexadecane & $99,0 \%$ & 613,2 & 610,2 & 615,39 \\
\hline $\mathrm{C}_{12} \mathrm{H}_{24}$ & 1-Dodecene & $99,0 \%$ & 635,0 & 633,8 & 636,71 \\
\hline $\mathrm{C}_{14} \mathrm{H}_{28}$ & 1-Tetradecene & $99,0 \%$ & 676,1 & 669,8 & 681,56 \\
\hline $\mathrm{C}_{16} \mathrm{H}_{32}$ & 1-Hexadecene & $99,0 \%$ & 480,9 & 471,4 & 489,25 \\
\hline $\mathrm{C}_{18} \mathrm{H}_{36}$ & 1-Octadecene & $99,0 \%$ & 587,2 & 578,6 & 600,69 \\
\hline $\mathrm{C}_{4} \mathrm{H}_{10} \mathrm{O}$ & 1-Butanol & $99,9 \%$ & 622,7 & 620,5 & 624,95 \\
\hline $\mathrm{C}_{6} \mathrm{H}_{14} \mathrm{O}$ & 1-Hexanol & $99,0 \%$ & 534,2 & 527,1 & 539,85 \\
\hline $\mathrm{C}_{8} \mathrm{H}_{18} \mathrm{O}$ & 1-Octanol & $99,0 \%$ & 403,9 & 395,3 & 410,99 \\
\hline $\mathrm{C}_{12} \mathrm{H}_{26} \mathrm{O}$ & 1-Dodecanol & $98,0 \%$ & 344,5 & 342,9 & 347,28 \\
\hline $\mathrm{C}_{6} \mathrm{H}_{12} \mathrm{O}$ & 1-Hexanal & $99,0 \%$ & 360,4 & 352,4 & 368,4 \\
\hline $\mathrm{C}_{8} \mathrm{H}_{16} \mathrm{O}$ & 1-Octanal & $99,0 \%$ & 236,0 & 232,6 & 239,49 \\
\hline $\mathrm{C}_{6} \mathrm{H}_{12} \mathrm{O}$ & Cyclohexanol & $98,0 \%$ & 312,7 & 302,5 & 326,17 \\
\hline $\mathrm{C}_{3} \mathrm{H}_{8} \mathrm{O}$ & 2-Propanol & $99,5 \%$ & 604,4 & 588,9 & 593,33 \\
\hline $\mathrm{C}_{7} \mathrm{H}_{8} \mathrm{O}$ & Benzyl alcohol & $98,0 \%$ & 303,0 & 290,1 & 328,72 \\
\hline $\mathrm{C}_{8} \mathrm{H}_{12} \mathrm{O}$ & 2-Butylfuran & $98,0 \%$ & 429,2 & 424,5 & 433,92 \\
\hline $\mathrm{C}_{5} \mathrm{H}_{6} \mathrm{O}_{2}$ & 2-Furylmethanol & $98,0 \%$ & 419,9 & 404,4 & 530,75 \\
\hline $\mathrm{C}_{5} \mathrm{H}_{8} \mathrm{O}_{2}$ & $\mathrm{v}$-Valerolacton & $98,0 \%$ & 505,6 & 491,1 & 525,69 \\
\hline $\mathrm{C}_{5} \mathrm{H}_{10} \mathrm{O}$ & 2-Methyltetrahydrofuran & $99,0 \%$ & 855,1 & 846,3 & 869,78 \\
\hline $\mathrm{C}_{6} \mathrm{H}_{8} \mathrm{O}$ & 2,5-Dimethylfuran & $98,0 \%$ & 226,3 & 252,6 & 348,37 \\
\hline $\mathrm{C}_{9} \mathrm{H}_{18} \mathrm{O}_{2}$ & 2-(butoxymethyl)tetrahydrofuran & $98,0 \%$ & 356,4 & 354,9 & 358,57 \\
\hline $\mathrm{C}_{10} \mathrm{H}_{18} \mathrm{O}_{3}$ & 2,2'-oxybis(methylene)bis(tetrahydrofuran) & $98,0 \%$ & 308,6 & 275,2 & 341,1 \\
\hline $\mathrm{C}_{8} \mathrm{H}_{18} \mathrm{O}$ & Di-n-Butylether & $98,0 \%$ & 620,5 & 611,7 & 629,36 \\
\hline $\mathrm{C}_{9} \mathrm{H}_{18} \mathrm{O}$ & Nonan-5-one & $99,0 \%$ & 450,8 & 440,8 & 456,86 \\
\hline $\mathrm{C}_{11} \mathrm{H}_{22} \mathrm{O}$ & 2-Undecanone & $98,0 \%$ & 478,9 & 447,0 & 513,93 \\
\hline $\mathrm{C}_{6} \mathrm{H}_{10} \mathrm{O}$ & Cyclohexanone & $99,0 \%$ & 512,9 & 509,6 & 516,19 \\
\hline
\end{tabular}

Table 2: The Wear scar diameters of the measured substances on the ball specimen 
The 13th Scandinavian International Conference on Fluid Power, SICFP2013, June 3-5, 2013, Linköping, Sweden

\begin{tabular}{|c|c|c|c|c|c|}
\hline \multirow[b]{2}{*}{ Formula } & \multirow[b]{2}{*}{ Substance } & \multirow[b]{2}{*}{ Purity } & \multicolumn{3}{|c|}{ Disc specimen } \\
\hline & & & $\begin{array}{c}\text { Averaged } W S D \\
{[\mu \mathrm{m}]}\end{array}$ & $\underset{[\mu \mathrm{m}]}{\operatorname{Maximum}} \boldsymbol{W S D}$ & $\underset{[\mu \mathrm{m}]}{\operatorname{Minimum}} W S D$ \\
\hline $\mathrm{C}_{7} \mathrm{H}_{16}$ & n-Heptane & $99,0 \%$ & 1454,6 & 1347,9 & 1542,3 \\
\hline $\mathrm{C}_{10} \mathrm{H}_{22}$ & n-Decane & $99,0 \%$ & 1470,7 & 1434,1 & 1502,8 \\
\hline $\mathrm{C}_{16} \mathrm{H}_{34} \mathrm{O}$ & n-Hexadecane & $99,0 \%$ & 1094,5 & 1081,8 & 1102,3 \\
\hline $\mathrm{C}_{12} \mathrm{H}_{24}$ & 1-Dodecene & $99,0 \%$ & 1148,1 & 1135,9 & 1165,1 \\
\hline $\mathrm{C}_{14} \mathrm{H}_{28}$ & 1-Tetradecene & $99,0 \%$ & 1163,7 & 1154,9 & 1172,4 \\
\hline $\mathrm{C}_{16} \mathrm{H}_{32}$ & 1-Hexadecene & $99,0 \%$ & 1008,0 & 989,7 & 1024,8 \\
\hline $\mathrm{C}_{18} \mathrm{H}_{36}$ & 1-Octadecene & $99,0 \%$ & 1064,0 & 1045,3 & 1080,3 \\
\hline $\mathrm{C}_{4} \mathrm{H}_{10} \mathrm{O}$ & 1-Butanol & $99,9 \%$ & 1101,3 & 1080,3 & 1128,6 \\
\hline $\mathrm{C}_{6} \mathrm{H}_{14} \mathrm{O}$ & 1-Hexanol & $99,0 \%$ & 1016,0 & 995,6 & 1030,6 \\
\hline $\mathrm{C}_{8} \mathrm{H}_{18} \mathrm{O}$ & 1-Octanol & $99,0 \%$ & 911,7 & 903,5 & 918,1 \\
\hline $\mathrm{C}_{12} \mathrm{H}_{26} \mathrm{O}$ & 1-Dodecanol & $98,0 \%$ & 859,6 & 852,3 & 866,9 \\
\hline $\mathrm{C}_{6} \mathrm{H}_{12} \mathrm{O}$ & 1-Hexanal & $99,0 \%$ & 868,4 & 786,5 & 929,8 \\
\hline $\mathrm{C}_{8} \mathrm{H}_{16} \mathrm{O}$ & 1-Octanal & $99,0 \%$ & 731,7 & 729,5 & 733,9 \\
\hline $\mathrm{C}_{6} \mathrm{H}_{12} \mathrm{O}$ & Cyclohexanol & $98,0 \%$ & 807,9 & 801,1 & 820,1 \\
\hline $\mathrm{C}_{3} \mathrm{H}_{8} \mathrm{O}$ & 2-Propanol & $99,5 \%$ & 1102,3 & 1067,2 & 1131,1 \\
\hline $\mathrm{C}_{7} \mathrm{H}_{8} \mathrm{O}$ & Benzyl alcohol & $98,0 \%$ & 789,4 & 773,4 & 798,2 \\
\hline $\mathrm{C}_{8} \mathrm{H}_{12} \mathrm{O}$ & 2-Butylfuran & $98,0 \%$ & 902,5 & 888,8 & 918,1 \\
\hline $\mathrm{C}_{5} \mathrm{H}_{6} \mathrm{O}_{2}$ & 2-Furylmethanol & $98,0 \%$ & 974,5 & 782,1 & 1062,8 \\
\hline $\mathrm{C}_{5} \mathrm{H}_{8} \mathrm{O}_{2}$ & Y-Valerolacton & $98,0 \%$ & 989,2 & 976,6 & 1010,2 \\
\hline $\mathrm{C}_{5} \mathrm{H}_{10} \mathrm{O}$ & 2-Methyltetrahydrofuran & $99,0 \%$ & 1358,1 & 1345,0 & 1369,8 \\
\hline $\mathrm{C}_{6} \mathrm{H}_{8} \mathrm{O}$ & 2,5-Dimethylfuran & $98,0 \%$ & 798,2 & 769,0 & 847,9 \\
\hline $\mathrm{C}_{9} \mathrm{H}_{18} \mathrm{O}_{2}$ & 2-(butoxymethyl)tetrahydrofuran & $98,0 \%$ & 864,5 & 855,2 & 874,2 \\
\hline $\mathrm{C}_{10} \mathrm{H}_{18} \mathrm{O}_{3}$ & 2,2'-oxybis(methylene)bis(tetrahydrofuran) & $98,0 \%$ & 806,0 & 785,0 & 831,8 \\
\hline $\mathrm{C}_{8} \mathrm{H}_{18} \mathrm{O}$ & Di-n-Butylether & $98,0 \%$ & 1133,0 & 1125,7 & 1137,4 \\
\hline $\mathrm{C}_{9} \mathrm{H}_{18} \mathrm{O}$ & Nonan-5-one & $99,0 \%$ & 957,1 & 944,4 & 969,2 \\
\hline $\mathrm{C}_{11} \mathrm{H}_{22} \mathrm{O}$ & 2-Undecanone & $98,0 \%$ & 960,0 & 956,1 & 964,9 \\
\hline $\mathrm{C}_{6} \mathrm{H}_{10} \mathrm{O}$ & Cyclohexanone & $99,0 \%$ & 998,0 & 986,8 & 1010,2 \\
\hline
\end{tabular}

Table 3: The Wear scar diameters of the measured substances on the disc specimen

\begin{tabular}{|l|l|c|c|c|}
\hline Formula & Substance & Purity & WSD Ball [ $\mu$ m] & WSD Disc [ $\mu$ m] \\
\hline $\mathrm{C}_{12} \mathrm{H}_{26}$ & n-Dodecane & $98,0 \%$ & 810,0 & 1329,1 \\
\hline $\mathrm{C}_{2} \mathrm{H}_{6} \mathrm{O}$ & Ethanol & $98,0 \%$ & 602,5 & 1112,7 \\
\hline $\mathrm{C}_{10} \mathrm{H}_{22} \mathrm{O}$ & 1-Decanol & $99,0 \%$ & 405,4 & 909,1 \\
\hline $\mathrm{C}_{10} \mathrm{H}_{20} \mathrm{O}$ & 1-Decanal & - & 205,0 & 746,0 \\
\hline $\mathrm{C}_{5} \mathrm{H}_{10} \mathrm{O}_{2}$ & Tetrahydro-2-furanylmethanol & $99,0 \%$ & 300,0 & 806,0 \\
\hline
\end{tabular}

Table 4: The Wear scar diameters measured by Fatemimougharimoughari [2] 